\title{
Exacerbation frequency and course of COPD
}

This article was published in the following Dove Press journal:

International Journal of COPD

20 September 2012

Number of times this article has been viewed

\section{David MG Halpin' \\ Marc Decramer ${ }^{2}$ \\ Bartolome Celli ${ }^{3}$ \\ Steven Kesten ${ }^{4}$ \\ Dacheng Liu ${ }^{4}$ \\ Donald P Tashkin ${ }^{5}$}

'Royal Devon and Exeter Hospital, Devon, UK; ${ }^{2}$ Respiratory Division, Katholieke Universiteit Leuven, University Hospital, KU Leuven, Belgium; '3Pulmonary Division, Brigham and Women's Hospital, Boston, MA; ${ }^{4}$ Boehringer Ingelheim Pharmaceuticals Inc, Ridgefield, CT; ${ }^{5}$ Department of Medicine, David Geffen School of Medicine at UCLA, Los Angeles, CA, USA
Correspondence: David MG Halpin Royal Devon and Exeter Hospital, Barrack Road, Exeter, EX2 5DW, United Kingdom

Tel +4401392402133

$\mathrm{Fax}+4401392402828$

Email d.halpin@nhs.net
Background: Exacerbations affect morbidity in chronic obstructive pulmonary disease (COPD). We sought to evaluate the association between exacerbation frequency and spirometric and health status changes over time using data from a large, long-term trial.

Methods: This retrospective analysis of data from the 4-year UPLIFT ${ }^{\circledR}$ (Understanding Potential Long-term Impacts on Function with Tiotropium) trial compared tiotropium with placebo. Annualized rates of decline and estimated mean differences at each time point were analyzed using a mixed-effects model according to subgroups based on exacerbation frequency (events per patient-year: $0,>0-1,>1-2$, and $>2$ ). Spirometry and the St George's Respiratory Questionnaire (SGRQ) were performed at baseline and every 6 months (also at one month for spirometry).

Results: In total, 5992 patients (mean age 65 years, 75\% male) were randomized. Higher exacerbation frequency was associated with lower baseline postbronchodilator forced expiratory volume in one second $\left(\mathrm{FEV}_{1}\right)(1.40,1.36,1.26$, and $1.14 \mathrm{~L})$ and worsening SGRQ scores (43.7, 44.1, 47.8, and 52.4 units). Corresponding rates of decline in postbronchodilator $\mathrm{FEV}_{1}$ (mL/year) were 40, 41, 43, and 48 (control), and 34, 38, 48, and 49 (tiotropium). Values for postbronchodilator forced vital capacity decline (mL/year) were 45, 56, 74, and 83 (control), and $43,57,83$, and 95 (tiotropium). The rates of worsening in total SGRQ score (units/year) were $0.72,1.16,1.44$, and 1.99 (control), and $0.38,1.29,1.68$, and 2.86 (tiotropium). The proportion of patients who died (intention-to-treat analysis until four years [1440 days]) for the entire cohort increased with increasing frequency of hospitalized exacerbations.

Conclusion: Increasing frequency of exacerbations worsens the rate of decline in lung function and health-related quality of life in patients with COPD. Increasing rates of hospitalized exacerbations are associated with increasing risk of death.

Keywords: chronic obstructive pulmonary disease, exacerbations, forced expiratory volume in one second, health status, tiotropium

\section{Background}

Exacerbations of chronic obstructive pulmonary disease (COPD) are of major importance. They have been associated with decline in health status ${ }^{1,2}$ and lung function. ${ }^{3-6}$ They are also associated with substantial mortality: estimates of hospital mortality rates for patients admitted with an exacerbation of COPD vary from $4 \%-30 \%,{ }^{7}$ and the 3 -month mortality rate after hospitalization in the UK is approximately $15 \%{ }^{8}$

Tiotropium is a once-daily, inhaled anticholinergic that provides at least 24 hours of improvement in airflow and hyperinflation in patients with COPD. ${ }^{9-12}$ The UPLIFT ${ }^{\circledR}$ 
(Understanding Potential Long-term Impacts on Function with Tiotropium) trial was undertaken to assess the long-term efficacy and safety of tiotropium, and the primary endpoint results have already been reported. ${ }^{13}$ Patients who participated in the UPLIFT ${ }^{\circledR}$ study were carefully observed over a period of 4 years. Quality-assured spirometry was performed every 6 months and the occurrence of exacerbations was identified using a standardized definition. This analysis was undertaken to assess the relationship between the frequency of exacerbations and exacerbation-related hospitalizations and lung function, health status, and mortality.

\section{Materials and methods}

We performed a post hoc analysis of data collected during the UPLIFT ${ }^{\circledR}$ study. Details of the study design and results for the primary and secondary endpoints have been previously reported. ${ }^{13,14}$ All patients gave written informed consent. The study was approved by local ethical review boards and conducted in accordance with the Declaration of Helsinki.

\section{Study design}

This was a 4-year, international, randomized, double-blind, placebo-controlled, parallel-group trial in patients with COPD. All patients in the study were permitted to continue use of all respiratory medications other than inhaled anticholinergics. The primary endpoints were the yearly rate of decline in prebronchodilator and postbronchodilator forced expiratory volume in one second $\left(\mathrm{FEV}_{1}\right)$ until completion of double-blind treatment. Secondary outcomes included other lung function measures, health-related quality of life as measured by the St George's Respiratory Questionnaire (SGRQ) total score, COPD exacerbations and related hospitalizations, and mortality. The treatment arms received tiotropium $18 \mu \mathrm{g}$ once daily or matching placebo delivered via the HandiHaler ${ }^{\circledR}$ inhalation device (Boehringer Ingelheim International GmbH, Ingelheim, Germany). All respiratory medications, other than inhaled anticholinergics, were permitted during the trial.

\section{Exacerbations}

Exacerbations were defined as an increase in or the onset of more than one respiratory symptom (cough, sputum, sputum purulence, wheezing, or dyspnea) lasting 3 days or more and requiring treatment with an antibiotic or a systemic corticosteroid. Data regarding exacerbations and related hospitalizations were collected using study-specific case report forms at every visit.

\section{Spirometry}

Spirometry was performed according to American Thoracic Society guidelines ${ }^{15}$ at randomization, at 30 days, every 6 months throughout the treatment period, and at a follow-up visit approximately 30 days after the end of study treatment. All sites were provided with identical spirometry equipment and study-specific software. A centralized quality assurance review of all spirometry data was performed during the study. ${ }^{14}$

\section{Health status}

Health status was measured using the SGRQ before prebronchodilator spirometry testing at baseline and every 6 months thereafter. $^{16}$

\section{Statistical analysis}

Data are reported as the mean \pm standard deviation unless otherwise specified. Statistical significance was considered at $P<0.05$. The rate of exacerbation (or hospitalized exacerbation) for a patient was calculated by the number of exacerbations (or hospitalized exacerbations) divided by the treatment duration. According to the rate of exacerbation (or hospitalized exacerbation), the patients were then categorized into four groups, ie, $0,>0-1,>1-2$, and $>2$ exacerbations per patient-year. Relationships to other outcomes were based on these categories of exacerbation rate. Decline of pulmonary function versus time was analyzed with random coefficient regression in which the $\mathrm{FEV}_{1}$ changed linearly after 30 days for each patient, intercepts and slopes were random, and the treatment effect was fixed. The same model was used for SGRQ decline versus time (from 6 months until completion of the study). All patients who underwent randomization received the study drug, and all patients who had at least three post randomization measurements of pulmonary function (with at least two of these for SGRQ) were used in the analysis. Mean FEV ${ }_{1}$ and SGRQ scores over time were estimated using a repeated-measures analysis of covariance model. Cox regression was used to calculate hazard ratios. Poisson regression with adjustment for treatment exposure and overdispersion was applied to the overall population to analyze the effect of baseline percentage-predicted postbronchodilator $\mathrm{FEV}_{1}$ on the rate of exacerbations. The Poisson regression contains the model treatment and baseline percentage-predicted postbronchodilator $\mathrm{FEV}_{1}$. Pearson correlation was used to explore the relationship between baseline percentage-predicted postbronchodilator $\mathrm{FEV}_{1}$ and the rate of exacerbations for the overall population. 


\section{Results}

\section{Study population}

There were 5992 randomized patients who received study medication (3006 control and 2986 tiotropium). The baseline demographics have been reported elsewhere. ${ }^{13}$ The mean patient age was $65 \pm 8$ years, $75 \%$ were men, and $30 \%$ were smoking at randomization. Mean postbronchodilator $\mathrm{FEV}_{1}$ was $1.32 \pm 0.44 \mathrm{~L}$ ( $48 \%$ predicted). Approximately $44.6 \%$ of the control population prematurely discontinued their study medication, compared with $36.2 \%$ of patients treated with tiotropium. At baseline, approximately $62 \%$ of patients used an inhaled steroid, $60 \%$ used a long-acting $\beta_{2}$-agonist (LABA), and $23 \%$ used theophylline-containing preparations.

\section{Exacerbations and related outcomes}

A total of 13,874 exacerbations were recorded during the study. Of 1942 patients who did not have an exacerbation, 1008 (52\%) did not complete the study. Of the remaining 4050 patients, $1450(36 \%)$ did not complete the study. Analysis of baseline characteristics by study completion status showed that, overall, a higher proportion of those who withdrew prematurely had severe or very severe COPD ( $n=2458$; Global Initiative for Obstructive Lung Disease [GOLD] stage III/IV 61.9\%) than those completing the trial $(\mathrm{n}=3534$, GOLD stage III/IV 46.2\%).
The baseline characteristics of patients grouped according to the mean frequency of exacerbations experienced during the trial, exacerbations in year 1 , and hospitalized exacerbations are shown in Tables $1-3$, respectively. Patients with a higher exacerbation frequency had lower lung function and worse health status, and were more likely to be receiving LABAs and inhaled steroids at baseline.

Overall, $32 \%$ of patients did not have an exacerbation during the study, and the proportion of patients with a mean exacerbation rate of more than two per year increased with increasing severity of airflow obstruction (Table 4).

Baseline postbronchodilator $\mathrm{FEV}_{1}$ (percentage predicted) was inversely associated with the frequency of exacerbations $(\mathrm{r}=-0.12,95 \%$ confidence interval $[\mathrm{CI}]-0.14$ to -0.09 ; $P<0.0001)$. A one percentage unit higher baseline postbronchodilator $\mathrm{FEV}_{1}$ percentage-predicted was associated with a $1.9 \%$ lower rate of exacerbation (95\% CI 1.6-2.1; $P<0.0001)$.

At all time points, tiotropium significantly improved morning prebronchodilator $\mathrm{FEV}_{1}$ compared with control $(P<0.01$, Figure 1); however, the size of the effect was attenuated in patients having more frequent exacerbations. The magnitude of improvement in postbronchodilator differences with tiotropium alone compared with the control group cannot be clearly stated because both groups received $400 \mu \mathrm{g}$ of albuterol and $80 \mu \mathrm{g}$ of ipratropium in addition to study drug.

Table I Patient baseline characteristics: exacerbation rate

\begin{tabular}{|c|c|c|c|c|c|c|c|c|}
\hline & \multicolumn{8}{|c|}{ Exacerbation rate (per patient-year) } \\
\hline & \multicolumn{2}{|l|}{0} & \multicolumn{2}{|l|}{$>0-1$} & \multicolumn{2}{|l|}{$>1-2$} & \multicolumn{2}{|l|}{$>2$} \\
\hline & Tiotropium & Control & Tiotropium & Control & Tiotropium & Control & Tiotropium & Control \\
\hline $\mathrm{N}$ & 985 & 957 & 1068 & 981 & 576 & 594 & 357 & 474 \\
\hline Age, years & $64(8)$ & $64(9)$ & $64(8)$ & $65(8)$ & $64(8)$ & $64(8)$ & $65(8)$ & $65(9)$ \\
\hline Male, \% & 76 & 74 & 77 & 76 & 73 & 74 & 74 & 70 \\
\hline Prebronchodilator $\mathrm{FEV}_{\mathrm{l}}, \mathrm{L}$ & $\mathrm{I} .20(0.4 \mathrm{I})$ & $\mathrm{I} .14(0.4 \mathrm{I})$ & I.I2(0.4I) & I. I $4(0.40)$ & I.0I (0.37) & $1.05(0.38)$ & $0.91(0.33)$ & $0.94(0.36)$ \\
\hline Postbronchodilator $\mathrm{FEV}_{1}$, L & $1.42(0.44)$ & $\mathrm{I} .37(0.46)$ & $1.36(0.45)$ & $1.37(0.43)$ & $1.24(0.40)$ & $1.28(0.42)$ & $1.12(0.37)$ & $1.15(0.40)$ \\
\hline Prebronchodilator $\mathrm{FEV}_{1}$, \% predicted & $43(12)$ & $4 I(I 2)$ & $40(12)$ & $4 \mid(12)$ & $37(\mathrm{II})$ & $38(12)$ & $34(\mathrm{II})$ & $35(11)$ \\
\hline Postbronchodilator $\mathrm{FEV}_{1}$, \% predicted & $51(12)$ & $49(13)$ & $48(13)$ & $49(12)$ & $45(12)$ & $46(13)$ & $42(12)$ & $43(12)$ \\
\hline GOLD II, \% & 57 & 49 & 48 & 50 & 39 & 43 & 25 & 29 \\
\hline III, \% & 37 & 41 & 43 & 42 & 50 & 45 & 57 & 56 \\
\hline $\mathrm{IV}, \%$ & 5 & 9 & 8 & 7 & 11 & 10 & 16 & 13 \\
\hline $\mathrm{BMI}, \mathrm{kg} / \mathrm{m}^{2}$ & $26(5)$ & $26(5)$ & $26(5)$ & $26(5)$ & $26(5)$ & $26(5)$ & $25(5)$ & $25(5)$ \\
\hline Current smokers, $\%$ & 32 & 32 & 27 & 30 & 29 & 29 & 30 & 25 \\
\hline Pack-years & $48(28)$ & $48(28)$ & $49(28)$ & $48(28)$ & $49(26)$ & $49(29)$ & $50(29)$ & $49(27)$ \\
\hline COPD duration, years & $10(7)$ & $9(7)$ & $10(7)$ & $9(7)$ & II (8) & $10(7)$ & $10(8)$ & $10(7)$ \\
\hline Baseline LABA use, $\%$ & 53 & 53 & 61 & 59 & 69 & 66 & 65 & 70 \\
\hline Baseline ICS use, \% & 55 & 55 & 60 & 60 & 71 & 69 & 71 & 75 \\
\hline Baseline ICS + LABA use, \% & 42 & 42 & 48 & 46 & 58 & 55 & 58 & 60 \\
\hline SGRQ, units & $44(17)$ & $44(17)$ & $44(17)$ & $44(17)$ & $48(17)$ & $48(16)$ & $53(16)$ & $52(16)$ \\
\hline
\end{tabular}

Note: Values expressed as means (SD) or percent of treatment group.

Abbreviations: BMI, body mass index; COPD, chronic obstructive pulmonary disease; FEV , forced expiratory volume in one second; GOLD, Global Initiative for Chronic Obstructive Lung Disease; ICS, inhaled corticosteroid; LABA, long-acting $\beta_{2}$-agonist; SGRQ, St George's Respiratory Questionnaire; SD, standard deviation. 
Table 2 Patient baseline characteristics: exacerbations in year I

\begin{tabular}{|c|c|c|c|c|}
\hline & \multicolumn{4}{|c|}{ Exacerbation during first year } \\
\hline & \multicolumn{2}{|l|}{ No } & \multicolumn{2}{|l|}{ Yes } \\
\hline & Tiotropium & Control & Tiotropium & Control \\
\hline $\mathrm{N}$ & 1770 & 1654 & 1216 & 1352 \\
\hline Age, years & $64(9)$ & $64(9)$ & $64(9)$ & $64(9)$ \\
\hline Male, \% & 76 & 75 & 75 & 73 \\
\hline Prebronchodilator $\mathrm{FEV}_{1}, \mathrm{~L}$ & $\mathrm{I} .15(0.4 \mathrm{I})$ & $\mathrm{I} .15(0.4 \mathrm{I})$ & $1.03(0.38)$ & $1.03(0.38)$ \\
\hline Postbronchodilator FEV, $\mathrm{L}$ & $1.38(0.44)$ & $1.37(0.45)$ & $1.25(0.42)$ & $\mathrm{I} .25(0.43)$ \\
\hline Prebronchodilator $\mathrm{FEV}_{1}$, \% predicted & $4 \mid(12)$ & $4 I(I 2)$ & $37(12)$ & $37(12)$ \\
\hline Postbronchodilator $\mathrm{FEV}_{1}$, \% predicted & $49(13)$ & $49(13)$ & $45(13)$ & $46(13)$ \\
\hline GOLD II, \% & 52 & 50 & 38 & 39 \\
\hline III, \% & 52 & 40 & 38 & 39 \\
\hline $\mathrm{IV}, \%$ & 7 & 8 & 11 & 10 \\
\hline $\mathrm{BMI}, \mathrm{kg} / \mathrm{m}^{2}$ & $26(5)$ & $26(5)$ & $26(5)$ & $26(5)$ \\
\hline Current smokers, $\%$ & 31 & 31 & 28 & 28 \\
\hline Pack years & $49(28)$ & $48(28)$ & $49(28)$ & $49(28)$ \\
\hline COPD duration, years & $10(8)$ & $9(7)$ & $10(7)$ & $10(8)$ \\
\hline Baseline LABA use, $\%$ & 56 & 55 & 66 & 66 \\
\hline Baseline ICS use, \% & 57 & 57 & 68 & 68 \\
\hline Baseline ICS + LABA use, $\%$ & 44 & 44 & 55 & 54 \\
\hline Baseline anticholinergic use, $\%$ & 43 & 44 & 50 & 47 \\
\hline SGRQ, units & $44(17)$ & $44(17)$ & $49(17)$ & $48(17)$ \\
\hline
\end{tabular}

Note: Values expressed as means (SD) or percent of treatment group.

Abbreviations: BMI, body mass index; COPD, chronic obstructive pulmonary disease; FEV , forced expiratory volume in one second; GOLD, Global Initiative for Chronic Obstructive Lung Disease; ICS, inhaled corticosteroid; LABA, long-acting $\beta_{2}$-agonist; SGRQ, St George's Respiratory Questionnaire; SD, standard deviation.

The rate of decline of postbronchodilator $\mathrm{FEV}_{1}$ and forced vital capacity (FVC) increased with increasing frequency of exacerbations. The rate of decline in postbronchodilator lung function was similar in patients in the control and tiotropium groups (Table 5); however, more patients in the control group experienced two or more exacerbations per year compared with the tiotropium group (474 versus 357 ). The rate of worsening of health status increased with increasing frequency of exacerbations (Table 5). The risk of a fatal event, whether or not information from prematurely discontinued

Table 3 Patient baseline characteristics: mean hospitalized exacerbation rate

\begin{tabular}{|c|c|c|c|c|c|c|c|c|}
\hline & \multicolumn{8}{|c|}{ Hospitalization rate (per patient-year) } \\
\hline & \multicolumn{2}{|l|}{0} & \multicolumn{2}{|l|}{$>0-1$} & \multicolumn{2}{|l|}{$>I-2$} & \multicolumn{2}{|l|}{$>2$} \\
\hline & Tiotropium & Control & Tiotropium & Control & Tiotropium & Control & Tiotropium & Control \\
\hline $\mathrm{N}$ & 2227 & 2195 & 573 & 605 & 115 & $|3|$ & 71 & 75 \\
\hline Age, years & $64(8)$ & 64(9) & $65(8)$ & $65(8)$ & $65(9)$ & $66(9)$ & $65(10)$ & $66(8)$ \\
\hline Male, \% & 74 & 73 & 80 & 77 & 76 & 70 & 76 & 69 \\
\hline Prebronchodilator $\mathrm{FEV}_{\mathrm{l}}$, L & $\mathrm{I} .15(0.4 \mathrm{I})$ & $1.14(0.40)$ & $0.98(0.36)$ & I.0I (0.36) & $0.88(0.33)$ & $0.84(0.31)$ & $0.86(0.30)$ & $0.87(0.36)$ \\
\hline Postbronchodilator $\mathrm{FEV}_{1}$, L & $\mathrm{I} .38(0.44)$ & $1.37(0.44)$ & $\mathrm{I} .20(0.4 \mathrm{I})$ & $\mathrm{I} .23(0.4 \mathrm{I})$ & $1.08(0.37)$ & $\mathrm{I} .04(0.36)$ & $\mathrm{I} .03(0.33)$ & $0.99(0.38)$ \\
\hline Prebronchodilator $\mathrm{FEV}_{1}, \%$ predicted & $4 I(12)$ & $4 I(I 2)$ & $36(11)$ & $37(11)$ & $33(11)$ & $32(\mathrm{II})$ & $33(10)$ & $34(\mathrm{II})$ \\
\hline Postbronchodilator $\mathrm{FEV}_{1}$, \% predicted & $50(12)$ & $49(12)$ & $43(12)$ & $45(13)$ & $40(11)$ & $40(12)$ & $39(11)$ & $40(12)$ \\
\hline GOLD II, \% & 53 & 50 & 30 & 36 & 21 & 23 & 23 & 19 \\
\hline III, \% & 40 & 42 & 55 & 49 & 61 & 57 & 52 & 55 \\
\hline IV, \% & 6 & 7 & 13 & 12 & 17 & 19 & 23 & 24 \\
\hline $\mathrm{BMI}, \mathrm{kg} / \mathrm{m}^{2}$ & $26(5)$ & $26(5)$ & $25(5)$ & $25(5)$ & $25(5)$ & $25(5)$ & $24(6)$ & $24(5)$ \\
\hline Current smokers, \% & 29 & 30 & 30 & 31 & 32 & 27 & 27 & 27 \\
\hline Pack years & $48(28)$ & $48(28)$ & $52(29)$ & $50(29)$ & $45(23)$ & $52(34)$ & $51(30)$ & $47(24)$ \\
\hline COPD duration, years & $10(7)$ & $10(7)$ & $10(8)$ & $10(7)$ & II (8) & $10(8)$ & $10(7)$ & $10(7)$ \\
\hline Baseline LABA use, \% & 59 & 58 & 64 & 66 & 66 & 62 & 59 & 67 \\
\hline Baseline ICS use, \% & 61 & 59 & 64 & 69 & 69 & 66 & 62 & 73 \\
\hline Baseline ICS + LABA use, \% & 48 & 47 & 52 & 54 & 60 & 53 & 47 & 57 \\
\hline Baseline anticholinergic use, \% & 43 & 43 & 52 & 51 & 51 & 48 & 59 & 53 \\
\hline SGRQ, units & $44(17)$ & $45(17)$ & $49(16)$ & $48(17)$ & $53(17)$ & $53(19)$ & $55(16)$ & $53(15)$ \\
\hline
\end{tabular}

Note: Values expressed as means (SD) or percent of treatment group.

Abbreviations: BMI, body mass index; COPD, chronic obstructive pulmonary disease; FEV , forced expiratory volume in one second; GOLD, Global Initiative for Chronic Obstructive Lung Disease; ICS, inhaled corticosteroid; LABA, long-acting $\beta_{2}$-agonist; SD, standard deviation; SGRQ, St George's Respiratory Questionnaire. 
Table 4 Distribution of exacerbation frequency by GOLD stage

\begin{tabular}{lllll}
\hline & \multicolumn{4}{l}{ Exacerbations per patient-year $(\mathbf{n})$} \\
\hline GOLD stage & 0 & $>0-$ I & $>$ I-2 & $>2$ \\
II, \% & 38 & 37 & 17 & 8 \\
III, \% & 28 & 33 & 21 & 18 \\
IV, \% & 26 & 29 & 23 & 23 \\
All stages, \% & 32 & 34 & 19 & 14 \\
\hline
\end{tabular}

Abbreviation: GOLD, Global Initiative for Chronic Obstructive Lung Disease.

patients was included, increased with increasing frequency of exacerbations (Table 6).

When analyzed according to whether or not patients had an exacerbation in the first year, there was no association between the occurrence of exacerbations and the rate of decline of prebronchodilator or postbronchodilator $\mathrm{FEV}_{1}$ or FVC (Table 7). Tiotropium significantly reduced the rate of decline in postbronchodilator $\mathrm{FEV}_{1}$ in patients who did not exacerbate in the first year. The pattern of decline in health status of those with an exacerbation was inconsistent between the two treatment groups, and the risk of a fatal event was greater in those with an exacerbation in both treatment groups (Table 7).

There was no relationship between the frequency of exacerbation-related hospitalizations and the rates of decline in prebronchodilator $\mathrm{FEV}_{1}$ or FVC (Table 8); however, the rates of decline in postbronchodilator $\mathrm{FEV}_{1}$ and $\mathrm{FVC}$ increased with increasing frequency of hospitalization. All-cause, lower respiratory, and cardiac mortality at day 1440 was increased in patients having more than two hospitalized exacerbations per year (Table 8), whether assessed during the treatment period or with the intention-to-treat dataset. Lower respiratory mortality, but not all-cause or cardiac mortality, was increased in patients who had an exacerbation in the first year (Table 7), whether assessed on treatment or on an intention-to-treat basis to day 1440 .

Compared with the subgroup of patients with two or more exacerbations, Cox regression analysis of all-cause

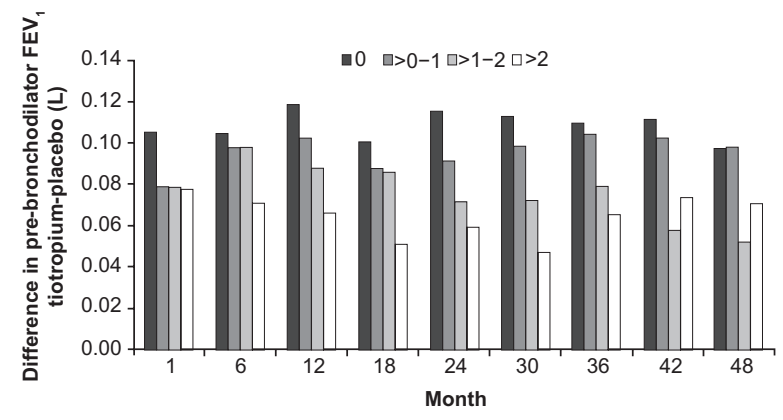

Figure I Treatment effect of tiotropium versus control by mean exacerbation frequency at different time points over 4 years.

Abbreviation: $\mathrm{FEV}_{1}$, forced expiratory volume in one second. mortality to day 1440 in patient subgroups defined by exacerbation frequency showed a hazard ratio of 0.555 (95\% CI 0.468-0.659) for the subgroup with no exacerbations, 0.295 (95\% CI 0.243-0.358) for the subgroup with 0-1 exacerbation, and 0.522 (95\% CI 0.430-0.633) for the subgroup with $1-2$ exacerbations.

\section{Discussion}

In the UPLIFT ${ }^{\circledR}$ trial, the use of tiotropium was associated with improvements in lung function and quality of life, and a reduction in the mean number of exacerbations by $14 \%$ $(P<0.001) .{ }^{13}$ The current post hoc analysis shows that lower baseline lung function was associated with an increasing frequency of exacerbations, whether or not patients received tiotropium. Patients treated with tiotropium had better lung function than those in the control group at all time points, irrespective of the frequency of exacerbations. A higher frequency of exacerbations over the study period was associated with an increase in the rate of decline in lung function and health-related quality of life, and more patients in the control group had a high frequency of exacerbations than in the tiotropium group. The relationship was less clear when patients were characterized according to whether they had an exacerbation in the first year or not. Increasing rates of hospitalized exacerbations were associated with an increased risk of death.

The effect of exacerbations and related hospitalizations on the rate of decline of lung function was seen most clearly in the postbronchodilator values where the effect of variability in bronchomotor tone had been minimized. Although early studies suggested frequent exacerbations were not associated with an increased rate of decline in lung function, ${ }^{17}$ subsequent studies have suggested that they may be associated., ${ }^{5,6}$ In the study by Donaldson et al, a relatively small number of patients $(n=109)$ followed over 4 years was divided into frequent and infrequent exacerbations based on the median rate. The difference between the groups was approximately $8 \mathrm{~mL} / \mathrm{year}^{5}$ The current analysis extends the observation in a much larger group of patients followed for 4 years. Furthermore, it shows a graded association between exacerbation frequency and annualized decline in $\mathrm{FEV}_{1}$ and $\mathrm{FVC}$.

In this, as in all other similar analyses, $3,5,6,18$ it is impossible to be certain of causality. It is unclear whether or not more frequent exacerbations cause an increased rate of decline in lung function through permanent damage, ${ }^{19-21}$ whether an increased rate of decline in lung function leads to more frequent exacerbations, or whether both reflect changes in the underlying level of inflammation in the lungs..$^{19,22,23}$ 
Table 5 Rate of change in spirometry and health status according to exacerbation frequency

\begin{tabular}{|c|c|c|c|c|c|c|c|c|}
\hline & \multicolumn{8}{|c|}{ Exacerbation rate } \\
\hline & \multicolumn{2}{|l|}{0} & \multicolumn{2}{|l|}{$>0-1$} & \multicolumn{2}{|l|}{$>1-2$} & \multicolumn{2}{|l|}{$>2$} \\
\hline & Tiotropium & Control & Tiotropium & Control & Tiotropium & Control & Tiotropium & Control \\
\hline \multicolumn{9}{|l|}{ Spirometry } \\
\hline Prebronchodilator $\mathrm{FEV}_{1}$, mL/year & $-29(2)$ & $-30(3)$ & $-28(2)$ & $-32(2)$ & $-34(3)$ & $-27(3)$ & $-34(5)$ & $-30(4)$ \\
\hline Postbronchodilator $\mathrm{FEV}_{1}$, mL/year & $-34(2)$ & $-40(3)$ & $-38(2)$ & $-4 \mid(2)$ & $-48(3)$ & $-43(3)$ & $-49(5)$ & $-48(4)$ \\
\hline Prebronchodilator FVC, mL/year & $-37(5)$ & $-32(6)$ & $-39(4)$ & $-39(4)$ & $-52(6)$ & $-46(6)$ & $-61(9)$ & $-38(9)$ \\
\hline Postbronchodilator FVC, mL/year & $-43(5)$ & $-45(6)$ & $-57(4)$ & $-56(4)$ & $-83(6)$ & $-74(6)$ & $-95(9)$ & $-82(8)$ \\
\hline Prebronchodilator SVC, mL/year & $-39(5)$ & $-39(6)$ & $-48(4)$ & $-43(4)$ & $-54(6)$ & $-4 \mid(8)$ & $-57(9)$ & $-44(8)$ \\
\hline Postbronchodilator SVC, mL/year & $-54(5)$ & $-52(6)$ & $-6 I(4)$ & $-6 \mid(4)$ & $-82(6)$ & $-74(6)$ & $-91(9)$ & $-87(8)$ \\
\hline \multicolumn{9}{|l|}{ Health status } \\
\hline SGRQ total score & $0.38(0.17)$ & $0.72(0.19)$ & $1.29(0.13)$ & $1.16(0.14)$ & $1.68(0.19)$ & $\mathrm{I} .44(0.20)$ & $2.86(0.3 \mathrm{I})$ & $1.99(0.28)$ \\
\hline
\end{tabular}

Notes: Annualized rate of change. Numbers in brackets are the SE values.

Abbreviations: $\mathrm{FEV}_{1}$, forced expiratory volume in one second; FVC, forced vital capacity; SGRQ, St George's Respiratory Questionnaire; SVC, slow vital capacity.

The observations regarding health status are similar to those for lung function. This analysis of the UPLIFT ${ }^{\circledR}$ study shows an association between the rate of decline in health status and mean annual frequency of exacerbations. A similar pattern of findings has been reported in other studies, ${ }^{1,24-27}$ and it has been suggested that the accelerated decline occurs because health status recovery after an exacerbation is significantly impaired if a further exacerbation occurs soon after. ${ }^{1}$

Previous analyses have suggested a greater annualized rate of decline in health status than the figures reported here, irrespective of whether patients had exacerbations or not. ${ }^{1,27}$ Data from the ISOLDE (Inhaled Steroids in Obstructive Lung Disease in Europe) trial noted that total SGRQ score declined by approximately two units per year in patients who did not have exacerbations and by about 2.6 units per year in those patients with exacerbations. ${ }^{27}$ These changes are larger than those reported here from the UPLIFT ${ }^{\circledR}$ trial. While there may be trial-related factors, it is quite possible that the increased use of maintenance respiratory medications over time, and the allowance for such use in the UPLIFT ${ }^{\circledR}$ trial, has improved the clinical course of COPD and the impact of exacerbations.

Hospitalization for an exacerbation of COPD is associated with significant mortality, ${ }^{8,28}$ and an increased frequency of exacerbations is associated with a significant increase in the risk of mortality over subsequent years in a dose-dependent manner. ${ }^{29}$ The present analysis confirms that frequent exacerbations, particularly those that result in hospitalization, increase the risk of death.

Overall, tiotropium reduced exacerbation rates compared with the control, and fewer tiotropium-treated patients had frequent exacerbations. Therefore, it is likely that the patients who continued to have frequent exacerbations, despite addition of tiotropium to their therapy, have different predispositions to exacerbations from those in the control group who had a similar frequency of exacerbations, despite the fact that their baseline characteristics were similar.

Nearly one-third of patients did not have an exacerbation during their time on the study. This is similar to the findings in the 3-year ECLIPSE (Evaluation of Chronic Obstructive Pulmonary Disease to Longitudinally Identify

Table 6 Mortality according to exacerbation frequency

\begin{tabular}{|c|c|c|c|c|c|c|c|c|}
\hline & \multicolumn{8}{|c|}{ Exacerbation rate } \\
\hline & \multicolumn{2}{|l|}{0} & \multicolumn{2}{|l|}{$>0-1$} & \multicolumn{2}{|l|}{$>1-2$} & \multicolumn{2}{|l|}{$>2$} \\
\hline & Tiotropium & Control & Tiotropium & Control & Tiotropium & Control & Tiotropium & Control \\
\hline \multicolumn{9}{|c|}{ During treatment, $\%$ of group } \\
\hline All-cause & 12.6 & 14.4 & 8.2 & 9.0 & 12.8 & 13.5 & 24.6 & 20.3 \\
\hline Lower respiratory & 2.9 & 2.6 & 2.5 & 2.3 & 5.2 & 6.6 & 12.6 & 11.2 \\
\hline Cardiac & 0.8 & 0.9 & 0.4 & 0.6 & 0.9 & 0.7 & 2.0 & 1.3 \\
\hline \multicolumn{9}{|c|}{$\begin{array}{l}\text { Including prematurely discontinued } \\
\text { patients to day I } 440, \% \text { of group }\end{array}$} \\
\hline All-cause & 14.5 & 18.0 & 8.7 & 10.1 & 15.5 & 16.5 & 29.4 & 25.7 \\
\hline Lower respiratory & 3.5 & 3.1 & 2.4 & 2.8 & 6.1 & 8.1 & 14.6 & 13.9 \\
\hline Cardiac & 0.8 & I.I & 0.4 & 0.6 & 0.9 & 0.8 & 2.2 & 1.9 \\
\hline
\end{tabular}


Table 7 Rate of change in spirometry, health status, and mortality according to occurrence of exacerbation in year I

\begin{tabular}{|c|c|c|c|c|}
\hline & \multicolumn{4}{|c|}{ Exacerbation in first year } \\
\hline & \multicolumn{2}{|l|}{ No } & \multicolumn{2}{|l|}{ Yes } \\
\hline & Tiotropium & Control & Tiotropium & Control \\
\hline \multicolumn{5}{|l|}{ Spirometry } \\
\hline Prebronchodilator $\mathrm{FEV}_{1}, \mathrm{~mL} /$ year & $-3 \mid(2)$ & $-35(2)$ & $-29(2)$ & $-25(2)$ \\
\hline Postbronchodilator FEV , mL/year & $-39(2)$ & $-44(2)$ & $-42(2)$ & $-40(2)$ \\
\hline Prebronchodilator FVC, mL/year & $-42(4)$ & $-42(4)$ & $-43(4)$ & $-35(4)$ \\
\hline Postbronchodilator FVC, mL/year & $-56(3)$ & $-58(4)$ & $-70(4)$ & $-64(4)$ \\
\hline Prebronchodilator SVC, mL/year & $-48(3)$ & $-46(4)$ & $-46(4)$ & $-36(4)$ \\
\hline Postbronchodilator SVC, mL/year & $-63(3)$ & $-6 I(4)$ & $-70(4)$ & $-69(4)$ \\
\hline \multicolumn{5}{|l|}{ Health status } \\
\hline Mean slope of total SGRQ score & $1.17(0.11)$ & $1.29(0.12)$ & $1.38(0.14)$ & $1.13(0.14)$ \\
\hline \multicolumn{5}{|l|}{ Mortality } \\
\hline \multicolumn{5}{|l|}{ During treatment (\% of group) } \\
\hline All-cause & 10.9 & 12.3 & 14.9 & 14.6 \\
\hline Lower respiratory & 3.3 & 2.9 & 5.9 & 6.8 \\
\hline Cardiac & 0.5 & 0.7 & 1.2 & 1.0 \\
\hline \multicolumn{5}{|l|}{$\begin{array}{l}\text { Including prematurely discontinued } \\
\text { patients to day I } 440 \text { (\% of group) }\end{array}$} \\
\hline All-cause & 12.6 & 15.0 & 18.3 & 18.3 \\
\hline Lower respiratory & 3.7 & 3.4 & 7.2 & 8.6 \\
\hline Cardiac & 0.6 & 0.9 & 1.3 & 1.3 \\
\hline
\end{tabular}

Notes: Annualized rate of change. Numbers in brackets are the SE values.

Abbreviations: FEV , forced expiratory volume in one second; FVC, forced vital capacity; SGRQ, St George's Respiratory Questionnaire; SVC, slow vital capacity.

Predictive Surrogate Endpoints) study. ${ }^{30}$ Further research is needed to determine whether there are phenotypes or genotypes that can identify those patients who are at low risk of exacerbations.

Discontinuation rates were higher in people who did not have an exacerbation than in those who did, but this may reflect the fact that more of those who withdrew had severe or very severe COPD at baseline, and may have spent less time in the study because of worsening symptoms, reducing the likelihood of observing an exacerbation during their time on the study.

We think it is unlikely that the observed relationships of exacerbation frequency and changes in the clinical endpoints

Table 8 Rate of change in spirometry, health status, and mortality according to hospitalized exacerbation frequency

\begin{tabular}{|c|c|c|c|c|c|c|c|c|}
\hline & \multicolumn{8}{|c|}{ Mean hospitalization rate } \\
\hline & \multicolumn{2}{|l|}{0} & \multicolumn{2}{|l|}{$>0-1$} & \multicolumn{2}{|l|}{$>1-2$} & \multicolumn{2}{|l|}{$>2$} \\
\hline & Tiotropium & Control & Tiotropium & Control & Tiotropium & Control & Tiotropium & Control \\
\hline \multicolumn{9}{|l|}{ Spirometry } \\
\hline Prebronchodilator $\mathrm{FEV}_{\Perp}$, mL/year & $-27(\mathrm{I})$ & $-29(2)$ & $-40(3)$ & $-3 \mid(3)$ & $-4 \mid(8)$ & $-39(8)$ & $-25(17)$ & $-34(23)$ \\
\hline Postbronchodilator $\mathrm{FEV}_{1}$, mL/year & $-35(2)$ & $-4 \mid(2)$ & $-53(3)$ & $-45(3)$ & $-60(8)$ & $-57(8)$ & $-59(17)$ & $-59(24)$ \\
\hline Prebronchodilator FVC, mL/year & $-37(3)$ & $-36(3)$ & $-60(6)$ & $-40(6)$ & $-70(16)$ & $-86(16)$ & $-36(36)$ & $-7 \mid(48)$ \\
\hline Postbronchodilator FVC, mL/year & $-50(3)$ & $-55(3)$ & $-9 \mid(5)$ & $-70(5)$ & $-122(16)$ & $-118(16)$ & $-117(34)$ & $-115(46)$ \\
\hline \multicolumn{9}{|l|}{ Health status } \\
\hline SGRQ total score & $0.80(0.10)$ & $0.95(0.11)$ & $2.31(0.19)$ & $1.70(0.19)$ & $4.21(0.55)$ & $3.34(0.55)$ & $3.99(1.17)$ & $4.22(1.66)$ \\
\hline \multicolumn{9}{|l|}{ Mortality } \\
\hline \multicolumn{9}{|l|}{ During treatment (\% of group) } \\
\hline All-cause & 9.6 & 11.3 & 15.9 & 14.5 & 35.7 & 31.3 & 40.8 & 32.0 \\
\hline Lower respiratory & 2.0 & 2.2 & 7.7 & 7.6 & 19.1 & 22.1 & 28.2 & 21.3 \\
\hline Cardiac & 0.7 & 0.8 & 1.0 & 0.5 & 0.9 & 1.5 & 1.4 & 2.7 \\
\hline \multicolumn{9}{|l|}{$\begin{array}{l}\text { Including prematurely discontinued } \\
\text { patients to day } 1440, \% \text { of group }\end{array}$} \\
\hline All-cause & 11.5 & 13.7 & 16.6 & 16.7 & 40 & 41.2 & 45.1 & 46.7 \\
\hline Lower respiratory & 2.6 & 2.7 & 7.5 & 8.6 & 21.7 & 29 & 29.6 & 29.3 \\
\hline Cardiac & 0.7 & 1.0 & 1.2 & 0.5 & 0.9 & 3.1 & 1.4 & 4.0 \\
\hline
\end{tabular}

Notes: Annualized rate of change. Numbers in brackets are the SE values.

Abbreviations: FEV , forced expiratory volume in one second; FVC, forced vital capacity; SGRQ, St George's Respiratory Questionnaire; SVC, slow vital capacity. 
over time arise as a consequence of confounding due, for example, to nonrandom discontinuation of patients and regression to the mean. This would lead to an apparently less rapid decline in lung function and health status, and differential discontinuation would increase exacerbation rates in the tiotropium-treated group because more severe patients would remain on the study for longer. However, this was not seen.

There are still some potential limitations to the analysis. The patients who took part were selected for involvement in a clinical trial and, therefore, may not be fully representative of patients seen in practice, particularly with regard to disease severity and the presence of comorbidities. However, the inclusion and exclusion criteria were relatively liberal, recruitment included a broad selection of patients with COPD and multiple comorbidities, and subjects were permitted to continue to use all prescribed respiratory medication except for anticholinergics, thus mimicking real-world conditions for pharmacotherapy.

\section{Conclusion}

COPD is a chronic illness with deterioration occurring over a number of years. In order to study factors affecting disease progression, prospective data from large cohorts such as the UPLIFT $^{\circledR}$ trial are essential. The long duration of the study, use of a standardized definition of exacerbation, and the fact that spirometry was centralized with rigorous quality, allow greater reliance to be placed on the current results, and more robust conclusions can be drawn about the effects of exacerbations on decline in lung function and health-related quality of life. Furthermore, the completeness of vital status information allows the effects of exacerbations and hospitalizations on mortality to be examined with confidence. The present analysis, based on a large dataset, supports the hypothesis that frequent exacerbations lead to an accelerated decline in lung function and health status, and an increased likelihood of death. These results have important and clinically relevant implications for defining treatment objectives. Reducing the frequency of exacerbations using pharmacotherapy should be a key objective of treatment given that, in addition to impacting the morbidity of COPD, achieving this should reduce mortality, lower health care expenditure, and slow disease progression.

\section{Disclosure}

We wish to acknowledge the editorial support of Natalie Dennis and Yamini Khirwadkar from PAREXEL, whose work was funded jointly by Boehringer Ingelheim and Pfizer. The study was funded by Boehringer Ingelheim and Pfizer. DL is an employee of Boehringer Ingelheim Pharmaceuticals Inc.
The other authors have no conflicts of interest to report for this work.

\section{References}

1. Seemungal TA, Donaldson GC, Paul EA, Bestall JC, Jeffries DJ, Wedzicha JA. Effect of exacerbation on quality of life in patients with chronic obstructive pulmonary disease. Am J Respir Crit Care Med. 1998;157(5 Pt 1):1418-1422.

2. Spencer S, Jones PW. Time course of recovery of health status following an infective exacerbation of chronic bronchitis. Thorax. 2003;58(7):589-593.

3. Anzueto A, Leimer I, Kesten S. Impact of frequency of COPD exacerbations on pulmonary function, health status and clinical outcomes. Int J Chron Obstruct Pulmon Dis. 2009;4:245-251.

4. Bates DV. The fate of the chronic bronchitic: a report of the tenyear follow-up in the Canadian Department of Veteran's Affairs coordinated study of chronic bronchitis. The J Burns Amberson Lecture of the American Thoracic Society: Am Rev Respir Dis. 1973;108(5): 1043-1065.

5. Donaldson GC, Seemungal TA, Bhowmik A, Wedzicha JA. Relationship between exacerbation frequency and lung function decline in chronic obstructive pulmonary disease. Thorax. 2002;57(10):847-852.

6. Kanner RE, Anthonisen NR, Connett JE. Lower respiratory illnesses promote FEV(1) decline in current smokers but not ex-smokers with mild chronic obstructive pulmonary disease: results from the lung health study. Am J Respir Crit Care Med. 2001;164(3):358-364.

7. Patil SP, Krishnan JA, Lechtzin N, Diette GB. In-hospital mortality following acute exacerbations of chronic obstructive pulmonary disease. Arch Intern Med. 2003;163(10):1180-1186.

8. Price LC, Lowe D, Hosker HS, Anstey K, Pearson MG, Roberts CM. UK National COPD Audit 2003: impact of hospital resources and organisation of care on patient outcome following admission for acute COPD exacerbation. Thorax. 2006;61(10):837-842.

9. Casaburi R, Mahler DA, Jones PW, et al. A long-term evaluation of once-daily inhaled tiotropium in chronic obstructive pulmonary disease. Eur Respir J. 2002;19(2):217-224.

10. Celli B, ZuWallack R, Wang S, Kesten S. Improvement in resting inspiratory capacity and hyperinflation with tiotropium in COPD patients with increased static lung volumes. Chest. 2003;124(5):1743-1748.

11. Maltais F, Hamilton A, Marciniuk D, et al. Improvements in symptomlimited exercise performance over $8 \mathrm{~h}$ with once-daily tiotropium in patients with COPD. Chest. 2005;128(3):1168-1178.

12. O'Donnell DE, Fluge T, Gerken F, et al. Effects of tiotropium on lung hyperinflation, dyspnoea and exercise tolerance in COPD. Eur Respir J. 2004;23(6):832-840.

13. Tashkin DP, Celli B, Senn S, et al. A 4-year trial of tiotropium in chronic obstructive pulmonary disease. N Engl J Med. 2008;359(15): 1543-1554.

14. Decramer M, Celli B, Tashkin DP, et al. Clinical trial design considerations in assessing long-term functional impacts of tiotropium in COPD: the UPLIFT trial. COPD. 2004;1(2):303-312.

15. [No authors listed]. Standardization of spirometry, 1994 update. American Thoracic Society. Am J Respir Crit Care Med. 1995;152(3): 1107-1136.

16. Jones PW, Quirk FH, Baveystock CM, Littlejohns P. A self-complete measure of health status for chronic airflow limitation. The St George's Respiratory Questionnaire. Am Rev Respir Dis. 1992; 145(6):1321-1327.

17. Fletcher C, Peto R, Tinker C, Speizer F. The Natural History of Chronic Bronchitis and Emphysema. An 8 Year Study of Working Men. Oxford, UK: Oxford University Press; 1976.

18. Kosmas EN, Zorpidou D, Vassilareas V, Roussou T, Michaelides S. Decreased C4 complement component serum levels correlate with the degree of emphysema in patients with chronic bronchitis. Chest. 1997;112(2):341-347. 
19. Crooks SW, Bayley DL, Hill SL, Stockley RA. Bronchial inflammation in acute bacterial exacerbations of chronic bronchitis: the role of leukotriene B4. Eur Respir J. 2000;15(2):274-280.

20. Gompertz S, O’Brien C, Bayley DL, Hill SL, Stockley RA. Changes in bronchial inflammation during acute exacerbations of chronic bronchitis. Eur Respir J. 2001;17(6):1112-1119.

21. Viglio S, Iadarola P, Lupi A, et al. MEKC of desmosine and isodesmosine in urine of chronic destructive lung disease patients. Eur Respir J. 2000;15(6):1039-1045.

22. Sethi S, Muscarella K, Evans N, Klingman KL, Grant BJ, Murphy TF. Airway inflammation and etiology of acute exacerbations of chronic bronchitis. Chest. 2000;118(6):1557-1565.

23. Stanescu D, Sanna A, Veriter C, et al. Airways obstruction, chronic expectoration, and rapid decline of FEV1 in smokers are associated with increased levels of sputum neutrophils. Thorax. 1996;51(3):267-271.

24. Llor C, Molina J, Naberan K, Cots JM, Ros F, Miravitlles M. Exacerbations worsen the quality of life of chronic obstructive pulmonary disease patients in primary healthcare. Int J Clin Pract. 2008;62(4): 585-592.
25. Miravitlles M, Ferrer M, Pont A, et al. Effect of exacerbations on quality of life in patients with chronic obstructive pulmonary disease: a 2 year follow up study. Thorax. 2004;59(5):387-395.

26. Miravitlles M, Calle M, Alvarez-Gutierrez F, Gobartt E, Lopez F, Martin A. Exacerbations, hospital admissions and impaired health status in chronic obstructive pulmonary disease. Qual Life Res. 2006;15(3):471-480.

27. Spencer S, Calverley PM, Burge PS, Jones PW. Impact of preventing exacerbations on deterioration of health status in COPD. Eur Respir J. 2004;23(5):698-702.

28. Halpin D. Mortality in COPD: inevitable or preventable? Insights from the cardiovascular arena. COPD. 2008;5(3):187-200.

29. Soler-Cataluna JJ, Martinez-Garcia MA, Roman SP, Salcedo E, Navarro M, Ochando R. Severe acute exacerbations and mortality in patients with chronic obstructive pulmonary disease. Thorax. 2005;60(11):925-931.

30. Hurst JR, Vestbo J, Anzueto A, et al. Susceptibility to exacerbation in chronic obstructive pulmonary disease. N Engl J Med. 2010;363(12): 1128-1138.

\section{Publish your work in this journal}

The International Journal of COPD is an international, peer-reviewed journal of therapeutics and pharmacology focusing on concise rapid reporting of clinical studies and reviews in COPD. Special focus is given to the pathophysiological processes underlying the disease, intervention programs, patient focused education, and self management protocols.

\section{Dovepress}

This journal is indexed on PubMed Central, MedLine and CAS. The manuscript management system is completely online and includes a very quick and fair peer-review system, which is all easy to use. Visit $\mathrm{http}: / / \mathrm{ww}$.dovepress.com/testimonials.php to read real quotes from published authors. 